\section{BMJ Open Respiratory Research}

\title{
Breathlessness dimensions association with physical and mental quality of life: the population based VASCOL study of elderly men
}

\author{
Lucas Cristea, ${ }^{1}$ Max Olsson, ${ }^{1}$ David Currow, ${ }^{2}$ Miriam Johnson, ${ }^{3}$ \\ Jacob Sandberg (D) , Magnus Ekström (D) ${ }^{1}$
}

To cite: Cristea L, Olsson M, Currow D, et al. Breathlessness dimensions association with physical and mental quality of life: the population based VASCOL study of elderly men. BMJ Open Resp Res 2021;8:e000990. doi:10.1136/ bmjresp-2021-000990

- Additional supplemental material is published online only. To view, please visit the journal online (http://dx.doi. org/10.1136/bmjresp-2021000990).

Received 11 May 2021 Accepted 19 October 2021

Check for updates

(C) Author(s) (or their employer(s)) 2021. Re-use permitted under CC BY. Published by BMJ.

${ }^{1}$ Faculty of Medicine, Department of Clinical Sciences Lund, Respiratory Medicine and Allergology, Lund University, Lund, Sweden

${ }^{2}$ Faculty of Heath, University of Technology Sydney, Sydney, New South Wales, Australia

${ }^{3}$ Hull York Medical School, The University of Hull, Hull, UK

${ }^{4}$ Center for Primary Health Care Research, Department of Clinical Sciences in Malmö, Lunds Universitet, Lund, Sweden

Correspondence to Dr Magnus Ekström; pmekstrom@gmail.com

\section{ABSTRACT}

Background Breathlessness is a multidimensional symptom prevalent in elderly affecting many aspects of life. We aimed to determine how different dimensions of breathlessness are associated with physical and mental quality of life (QoL) in elderly men.

Methods This was a cross-sectional, population-based analysis of 672 men aged 73 years in a Swedish county. Breathlessness was assessed using Dyspnoea-12 (D-12) and Multidimensional Dyspnoea Profile (MDP), and QoL using the Short Form 12 physical and mental scores. Scores were compared as z-scores across scales and analysed using multivariable linear regression, adjusted for smoking, body mass index and the presence of respiratory and cardiovascular disease.

Results Worse breathlessness was related to worse physical and mental QoL across all the D-12 and MDP dimension scores. Physical QoL was most strongly associated with perceptional breathlessness scores, D-12 total and physical scores $(95 \% \mathrm{Cl}-0.45$ to -0.30$)$. Mental QoL was more strongly influenced by affective responses, MDP emotional response score $(95 \% \mathrm{Cl}-0.61$ to -0.48$)$. Head-to-head comparison of the instruments confirmed that D-12 total and physical scores most influenced physical QoL, while mental QoL was mostly influenced by the emotional responses captured by the MDP.

Conclusion Breathlessness dimensions and QoL measures are associated differently. Physical QoL was most closely associated with sensory and perceptual breathlessness dimensions, while emotional responses were most strongly associated with mental QoL in elderly men. D-12 and MDP contribute complimentary information, where affective and emotional responses may be related to function, deconditioning and QoL.

\section{INTRODUCTION}

Breathlessness is a dominant symptom in cardiorespiratory disease and other severe illnesses ${ }^{1}$ and is prevalent in the population, affecting the everyday life of about $20 \%$ of elderly (aged $>70$ ) in the community. ${ }^{2-5}$ Chronic breathlessness ${ }^{6}$ often remains an invisible problem for healthcare professionals, ${ }^{7}$ even though it is an important cause

\section{Key messages}

Which breathlessness dimensions were associated with the physical and mental quality of life (QoL) in elderly men?

- Sensory and perceptual breathlessness dimensions were associated with physical QoL while emotional responses were associated with mental QoL.

- We show that different dimensions of breathlessness are associated with worse physical and mental QoL.

of suffering, adverse events, health service utilisation and reduced function. It is strongly associated with poorer prognosis, ${ }^{8}$ anxiety, depression, fear ${ }^{9}$ and worse health-related quality of life (QoL). ${ }^{2}$

Breathlessness is a multidimensional symptom, influenced by different cognitive, physiological, psychological and environmental factors. ${ }^{910}$ To gain an understanding of the person's experienced symptom, multiple dimensions of breathlessness need to be considered including its intensity, sensory quality (descriptors), unpleasantness/discomfort, emotional responses (such as anxiety, sense of depression or frustration) and its impact on QoL. ${ }^{2}$ Multidimensional measurement is therefore important to adequately capture changes in the person's health status and treatment effects. The high prevalence of depression and anxietycompounded by emotional responses to the symptom itself, may impair the person's sense of self efficacy, function ${ }^{11}$ and further worsen QoL. ${ }^{12} 13$

Physical limitation from breathlessness, measured using the modified Medical Research Council (mMRC) score $^{14}$ has been associated with worse health-related QoL in adults, including both worse physical and mental QoL measured using the Short Form-12 (SF-12). ${ }^{215}$ 
Multiple dimensions of breathlessness can be assessed using the validated instruments Dyspnoea-12 (D-12) ${ }^{16}$ and the Multidimensional Dyspnoea Profile (MDP). ${ }^{17}$ Both instruments are widely used and MDP was recently validated in elderly people ${ }^{18}$ and used for patients with chronic obstructive pulmonary disease (COPD). ${ }^{19}$ QoL can be assessed using a number of validated tools including the generic SF-12. ${ }^{20}$ Neither the D-12 nor the MDP used the SF-12 (nor SF-36) in their validation studies.

Data are limited on breathlessness in the general population and in relation to QoL. Since this is a populational sample, we expected to find a lower prevalence of conditions and symptoms. In elderly patients' symptoms are more common than at a younger age, and a study on a populational level can increase the knowledge of public health among elderly. Population studies have mainly used the mMRC scale, which relates to the activity or exertion required to induce breathlessness and not the severity of the breathlessness per se. ${ }^{14}$ No study has evaluated which dimensions of breathlessness that most strongly impact physical and mental QoL. This knowledge is important as different dimensions may have particularly strong effects on different outcomes including QoL, and thus be important treatment targets. ${ }^{21}$ We hypothesise that breathlessness dimensions associate differently with QoL, and that affective and emotional responses, such as anxiety and fear, most strongly influence mental QoL.

The primary aim of this study was to evaluate which dimensions of breathlessness, measured using D-12 and MDP, were most strongly associated with physical and mental QoL in elderly men in the general population. Second, we performed a head-to-head comparison between D-12 and MDP, to evaluate which of their corresponding dimension scores (D12 total/MDP A1; D12 physical/MDP perception; D-12 affective/MDP emotional) most independently and strongly captured physical and mental QoL.

\section{METHODS}

\section{Study design and population}

This was a cross-sectional, population-based analysis of 73-year-old men in the VAScular disease and Chronic Obstructive Lung disease (VASCOL) study. The design and measurements of the VASCOL study has been detailed elsewhere. ${ }^{22}$ VASCOL included 1302 men aged 65 years in 2011-2012 who participated in screening for aortic aneurysm and who consented to participate in a longitudinal follow-up study. No patient-reported outcomes were assessed at baseline. In 2019, a postal survey including validated Swedish versions D-12, ${ }^{16}{ }^{23} \mathrm{MDP}^{1724}$ and SF-12 $2^{20}$ were sent to participants in the VASCOL study who were still alive and with a known address. The present analysis included participants who had available data on the evaluated D-12, MDP and SF-12 scores.
Assessments

Descriptives

Self-reported variables included height $(\mathrm{cm})$, weight (kg), smoking status (current, former or never-smoker), smoking exposure (years and mean number of cigarettes per day) and the presence of physician diagnosed conditions. ${ }^{22}$

\section{Breathlessness}

D-12 comprises 12 items (descriptors) each scored a 4-point scale of 0 (none), 1 (mild), 2 (moderate) or 3 (severe).$^{23}$ The first seven items pertain to the physical domain (D-12 physical) of breathlessness, while the remaining five items pertain to the affective domain (D-12 affective). The range for D-12 total score is 0-36: $0-21$ for the physical score; and $0-15$ for the affective score. Higher D-12 scores indicate worse breathlessness. ${ }^{23}$ D-12 is validated to be completed as a postal questionnaire. ${ }^{16}$

The MDP comprises 11 items which are rated on $0-10$ Numerical Rating Scales, divided into three domains that were evaluated: (1) the MDP A1 which is the total unpleasantness or discomfort of breathing; (2) the MDP perception score (range 0-60) which is the sum of A1 and the intensities of five sensory qualities (muscle work or effort; air hunger; chest tightness or constriction; mental effort or concentration and breathing a lot); and (3) MDP emotional response score (range 0-50) with is the sum of the intensities for each of five emotional responses (depression; anxiety; frustration; anger and fright). Higher MDP scores reflect worse breathlessness. ${ }^{24} \mathrm{MDP}$ is also validated to be completed as a postal questionnaire. ${ }^{17}$

\section{Quality of life}

SF-12 comprises 12 items divided into a physical and a mental subscore with six questions and ranging 0-100 each. Higher scores indicate worse QoL. ${ }^{20}{ }^{22}$ Questions regarding the physical QoL include limitations in activities, accomplishments and pain interference, while the mental score pertains to questions on accomplishments, energy, mood and social time.

The time period used in this study for all breathlessness and QoL instruments was 'during the last 2 weeks' ${ }^{22}$ The V.2 of SF-12 was used for the measurements.

\section{Statistical analyses}

Characteristics of the participants at the time of the questionnaire (baseline) were tabulated. Representativeness of the participants compared with the underlying population sample was assessed by comparing characteristics at the initial assessment (2011-2012) between people who were included and not included in the present analysis. Sensitivity analysis for the included and excluded groups were analysed using $\chi^{2}$ test.

Associations for each breathlessness score for MDP (A1, perception and emotional response scores) and D-12 (total, physical and affective scores) with SF-12 physical 
and mental QoL scores were analysed using linear regression. MDP has a wider range $(0-10)$ which makes it more suitable for linear regression compared with D-12 (0-3) in which each score corresponds to a category. MDP was designed to be used mainly as individual scales, to measure one or several dimensions depending on the research question while D-12 was constructed to yield a summary score to describe the overall level of breathlessness. Unadjusted and adjusted models were conducted for the potential confounders: body mass index (BMI), smoking status, pack-years of smoking, presence of cardiovascular disease (myocardial infarction, heart failure, valvopathies, atrial fibrillation or stroke) and respiratory disease (COPD, asthma or other lung disease). Confounders were selected based on previous literature ${ }^{2324}$ and subject matter knowledge using a directed acyclic graph (DAG; www.dagitty.net). Multicollinearity was checked with a correlation matrix of the included variables. Adjustment for age and sex was not needed; all participants were men aged 73 years. Level of physical activity was not included in the main model, as it could mediate (through deconditioning) part of the effect of breathlessness on QoL. A sensitivity analysis also including physical activity was performed.

To compare the strength of associations between breathlessness dimensions and QoL, all breathlessness and QoL scores were log transformed to obtain a more normal distribution and converted into z-scores ([raw score - mean]/SD of the score). Z-scores are an established method to enable comparisons of scores across scales with different ranges. Normality of the breathlessness scores and outcomes were assessed using distribution plots. Estimates were expressed with 95\% CIs. Estimates are interpreted as the mean change (in SDs) of the QoL score for each SD increase in the breathlessness score.

For head-to-head comparison of the associations with QoL between D-12 and MDP, regression models were conducted with the corresponding score from each instrument (D-12 total/MDP A1; D12 physical/MDP perception; and D-12 affective/MDP emotional, respectively), adjusting for the confounders. The estimates are interpreted as the strength of association independent of that of the corresponding score of the other instrument. Statistical analyses were performed using Stata V.16.0.

Written individual informed consent was obtained from all participants.

\section{Patient and public involvement}

Patients or the public were not involved in the design, conduct, reporting or dissemination plans of our research.

\section{RESULTS}

\section{Participants}

Out of the 1302 participants in the initial VASCOL population sample in 2011-2012, 1193 (92\%) participants were still alive and had a known address in 2019. Out of these participants, 907 (76\%) participated in the 2019 follow-up by returning the questionnaire. After exclusion of 235 participants due to missing data on D-12, MDP or SF-12, a total of 672 men aged 73 years were included in the analysis.

Participant characteristics are shown in table 1. Any breathlessness (score $\geq 1$ ) was reported for $\mathrm{mMRC}$ by 97 (14\%), for D-12 total by $196(29 \%)$ and for MDP A1 by $189(28 \%)$. Moderate to severe breathlessness, defined as MDP A1 $\geq 4$, was reported by $29(4 \%)$. Compared with

Table 1 Characteristics of 672 men aged 73 years from the general population

\begin{tabular}{|c|c|}
\hline Factor & Value \\
\hline Age, mean (SD) & $73.2(0.7)$ \\
\hline BMI, mean (SD) & $27.2(3.9)$ \\
\hline Ever smoked, n (\%) & $436(65.7)$ \\
\hline Missing & $8(1.2)$ \\
\hline Pack-years of smoking, median (IQR) & $5.4(0-11.4)$ \\
\hline \multicolumn{2}{|l|}{ Morbidities, n (\%) } \\
\hline Respiratory disease & $58(8.6)$ \\
\hline Asthma & $34(5.1)$ \\
\hline COPD & $26(3.9)$ \\
\hline Other respiratory diseases & $8(1.2)$ \\
\hline Cardiovascular disease & $201(29.9)$ \\
\hline Angina pectoris & $48(7.1)$ \\
\hline Atrial fibrillation & $104(15.5)$ \\
\hline Heart failure & $27(4.0)$ \\
\hline Myocardial infarction & $66(9.8)$ \\
\hline Valvopathies & $36(5.4)$ \\
\hline Diabetes mellitus & $93(13.8)$ \\
\hline Rheumatological disease & $31(4.6)$ \\
\hline Stroke & $50(7.4)$ \\
\hline \multicolumn{2}{|l|}{ Breathlessness and QoL } \\
\hline \multicolumn{2}{|l|}{ mMRC, n (\%) } \\
\hline 0 & $447(66.5)$ \\
\hline 1 & $97(14.4)$ \\
\hline 2 & $54(8.0)$ \\
\hline 3 & $26(3.9)$ \\
\hline 4 & $32(4.8)$ \\
\hline Missing & $16(2.4)$ \\
\hline D-12 total score, mean (SD) & $1.66(4.16)$ \\
\hline D-12 physical score, mean (SD) & $1.08(2.52)$ \\
\hline D-12 affective score, mean (SD) & $0.57(1.81)$ \\
\hline MDP A1 unpleasantness score, mean (SD) & $0.71(1.37)$ \\
\hline MDP perception score, mean (SD) & $2.63(6.48)$ \\
\hline MDP emotional response score, mean (SD) & $1.76(5.09)$ \\
\hline SF-12 physical QoL, mean (SD) & $46.66(9.03)$ \\
\hline SF-12 mental QoL, mean (SD) & $54.41(8.93)$ \\
\hline
\end{tabular}

Data presented as mean (SD) or frequency (\%). Percentages may not sum to 100 due to overlapping categories.

$\mathrm{BMI}$, body mass index; COPD, chronic obstructive pulmonary disease; D-12 Dyspnoea-12; MDP, Multidimensional Dyspnoea Profile; mMRC, modified medical research council; QoL, quality of life; SF-12, Short Form-12. 
Table 2 Association for each breathlessness dimension with physical or mental quality of life assessed using the Short Form $12(\mathrm{SF}-12)$

Association with SF-12 physical score, adjusted* beta $(95 \% \mathrm{Cl})$
Association with SF-12 mental score, adjusted* beta $(95 \% \mathrm{Cl})$

\begin{tabular}{|c|c|c|}
\hline \multicolumn{3}{|l|}{ D-12 } \\
\hline Total score & $-0.38(-0.46$ to -0.31$)$ & $-0.37(-0.45$ to -0.29$)$ \\
\hline Physical score & $-0.38(-0.45$ to -0.30$)$ & $-0.36(-0.44$ to -0.28$)$ \\
\hline Affective score & $-0.33(-0.4$ to -0.26$)$ & $-0.33(-0.41$ to -0.25$)$ \\
\hline \multicolumn{3}{|l|}{ MDP } \\
\hline A1 unpleasantness score & $-0.33(-0.40$ to -0.25$)$ & $-0.34(-0.42$ to -0.26$)$ \\
\hline Perception score & $-0.30(-0.37$ to -0.22$)$ & $-0.32(-0.40$ to -0.24$)$ \\
\hline Emotional response score & $-0.24(-0.31$ to -0.17$)$ & $-0.50(-0.57$ to -0.43$)$ \\
\hline \multicolumn{3}{|l|}{ Descriptors } \\
\hline Muscle work or effort & $-0.23(-0.30$ to -0.15$)$ & $-0.25(-0.33$ to -0.17$)$ \\
\hline Air hunger & $-0.23(-0.30$ to -0.16$)$ & $-0.25(-0.33$ to -0.16$)$ \\
\hline Chest tightness or constriction & $-0.21(-0.28$ to -0.14$)$ & $-0.27(-0.35$ to -0.19$)$ \\
\hline Mental effort or concentration & $-0.21(-0.28$ to -0.14$)$ & $-0.27(-0.35$ to -0.19$)$ \\
\hline Breathing a lot & $-0.17(-0.24$ to -0.10$)$ & $-0.21(-0.29$ to -0.13$)$ \\
\hline \multicolumn{3}{|l|}{ Emotional responses } \\
\hline Depression & $-0.17(-0.24$ to -0.09$)$ & $-0.55(-0.61$ to -0.48$)$ \\
\hline Anxiety & $-0.21(-0.28$ to -0.14$)$ & $-0.51(-0.59$ to -0.44$)$ \\
\hline Frustration & $-0.24(-0.31$ to -0.17$)$ & $-0.44(-0.51$ to -0.36$)$ \\
\hline Anger & $-0.18(-0.25$ to -0.10$)$ & $-0.41(-0.49$ to -0.34$)$ \\
\hline Fright & $-0.21(-0.28$ to -0.14$)$ & $-0.46(-0.54$ to -0.39$)$ \\
\hline
\end{tabular}

To be able to compare the strengths of the associations between the different scales, all scores were log transformed (to yield more normal distributions) and analysed as z-scores. Associations are by linear regression each breathlessness score separately, adjusted for confounders.

*Adjusted for the confounders smoking history, packet-years, BMI, respiratory diseases, and cardiovascular diseases. BMI, body mass index; D-12, Dyspnoea-12; MDP, Multidimensional Dyspnoea Profile.

people excluded due to missing data, included participants had fewer current smokers $(11 \%$ vs $15 \%$; $=0.015)$ and fewer morbidities such as diabetes mellitus $(7 \%$ vs $13 \%$; $\mathrm{p}<0.001$ ), online supplemental table S1.

\section{Breathlessness dimensions and QoL}

Associations of different breathlessness dimensions with QoL are shown unadjusted (online supplemental table S2) and adjusted for confounders in table 2. Worse breathlessness was independently associated with worse physical and mental QoL, across all the D-12 and MDP scores. However, the strength of associations differed between the breathlessness dimensions. Physical QoL was most strongly associated with the D-12 scores and MDP A1. In contrast, mental QoL was most strongly associated with the MDP emotional response summary score $(-0.50$; $95 \%$ CI -0.57 to -0.43$)$ and across the individual MDP emotional responses (table 2).

\section{Comparison of D-12 and MDP}

To explore which of the instruments' dimension scores that were most strongly and independently associated with the QoL outcomes, the corresponding scores from D-12 and MDP were evaluated concurrently in the same models 'head-to-head', as shown in table 3 .

This analysis confirmed that physical QoL was most strongly associated with the D-12 scores. When adjusting for the corresponding D-12 score, the MDP A1 and subdomain scores no longer showed any independent association with physical QoL.

Mental QoL was most strongly associated with the MDP emotional response score, which was the strongest among all evaluated associations $(-0.51 ; 95 \% \mathrm{CI},-0.61$ to -0.42$)$, table 3. Controlling for MDP emotional response, the D-12 affective score showed no independent association with mental QoL. The findings were similar in a sensitivity analysis also adjusting for the level of physical activity.

\section{DISCUSSION}

\section{Main findings}

Worse breathlessness, across all dimensions measured using D-12 and MDP, was strongly associated with worse physical and mental QoL. These associations were independent of potential confounders including smoking, $\mathrm{BMI}$ and the presence of respiratory and cardiovascular 
Table 3 Comparison between D-12 and MDP of associations with physical and mental quality of life, adjusted for confounders

\begin{tabular}{lll}
\hline Outcome & D-12 score & MDP score \\
\hline SF-12 & Total & A1 \\
physical & $-0.32(-0.42$ to -0.21$)$ & $-0.09(-0.20$ to 0.02$)$ \\
score & Physical & Perception \\
& $-0.33(-0.44$ to -0.22$)$ & $-0.06(-0.16$ to 0.04$)$ \\
& Affective & Emotional response \\
& $-0.30(-0.39$ to -0.21$)$ & $-0.04(-0.13$ to 0.05$)$ \\
SF-12 & Total & A1 \\
mental & $-0.27(-0.39$ to -0.14$)$ & $-0.14(-0.26$ to -0.01$)$ \\
score & Physical & Perception \\
& $-0.26(-0.38$ to -0.14$)$ & $-0.13(-0.25$ to -0.01$)$ \\
& Affective & Emotional response \\
& $0.01(-0.08$ to 0.11$)$ & $-0.51(-0.61$ to -0.42$)$ \\
\hline
\end{tabular}

Associations of corresponding scores of D-12 and the MDP, analysed concurrently in the same model, with physical and mental QoL. QoL was assessed using the SF-12 questionnaire. To be able to compare the strengths of the associations between the different scales, all scores were log transformed (to yield more normal distributions) and analysed as z-scores.

All models were adjusted for the confounders smoking history, packet-years, BMI, cardiovascular diseases, and respiratory diseases.

BMI, body mass index; D-12, Dyspnoea-12; MDP, Multidimensional Dyspnoea Profile; QoL, quality of life; SF12, Short Form 12.

disease. However, breathlessness dimensions influenced QoL differently. Physical QoL was most strongly related to sensory and perceptual dimension scores most strongly captured by D-12. In contrast, mental QoL associated most strongly with emotional responses to breathlessness captured by the MDP.

\section{What this study adds}

This is the first study to incorporate D-12 and MDP into the health assessment of the participants in a general population sample. We expected to find a lower prevalence of breathlessness in our populational sample. The findings extend those of the cross-sectional study by Currow et al that worsening disability from chronic breathlessness (measured using mMRC) was associated with increasingly impaired physical and mental QoL in an adult population, majority of the adults were nonsmokers aged between 15-44 years. ${ }^{2}$

Morélot-Panzini et al also showed high correlates of MDP-A2 with SF-12 mental component and HADS in patients with COPD. ${ }^{25}$ We now show that different dimensions of breathlessness are associated with worse physical and mental QoL, and that the strengths of the associations differ between breathlessness dimensions and by type of QoL. D-12 scores were more strongly associated with the physical QoL, while emotional responses to breathlessness measured using the MDP most strongly influenced mental QoL. This is the first headto-head comparison of D-12 and MDP, showing that the instruments contribute complementary information. D-12 captured both physical and mental factors-in line with the aim, development and multidimensional nature of the instrument ${ }^{26}$ - while MDP most strongly captured affective and emotional responses strongly linked to mental QoL. This analysis also showed that when analysing physical QoL with D-12 and mental QoL using MDP, respectively, measuring and adding the corresponding score from the other instrument added no further independent information in terms of their association with QoL.

The present findings are in line with report that breathlessness catastrophising (exaggerated negative cognitive-emotional orientation towards an actual or anticipated noxious stimuli) was related to poorer QoL in adults with cystic fibrosis, ${ }^{27}$ and that depression, pain and a less constructive emotional response to breathlessness are unique predictors of poorer health-related QoL. This might have therapeutic implications as, like in pain catastrophising, a more adverse affective and emotional response to breathlessness (such as in breathlessness catastrophising) may undermine the response to the interventions ${ }^{28}$ including to opioids. ${ }^{29}$ High scores of emotional responses might be related to less effective mental coping which could be measured with Coping Scale for Adults.

\section{Strengths and limitations}

Strengths of this study include the use of validated and established multidimensional breathlessness instruments, the relatively large sample size and available data that allowed several potentially important confounders to be addressed in the analysis. Another strength is that SF-12 V.2 is a valid instrument with independent subscales, which are not correlated with one another as shown by Ware et al. ${ }^{30}$

A limitation of this study is the fact that only 73-year-old men were studied, they were only included because only men participated in the VASCOL study. While this effectively avoids any bias related to sex and age, generalisability for women and other age groups may be limited, and future follow-ups in the VASCOL study is planned to also include women and younger age groups. ${ }^{22}$ Also, most participants were relatively healthy and few reported severe breathlessness, which is to be expected in a population sample like this. The prevalence of COPD and asthma is slightly lower but like other studies of men and women in the same age, and as expected the prevalence of COPD is higher in our study than studies of younger age groups. ${ }^{31}{ }^{32}$ Suggested next steps are to evaluate the impact of different breathlessness dimensions in people with more severe underlying disease and severe breathlessness. 


\section{Implications}

The present findings have several implications. First, the differing associations with QoL support the importance of measuring multiple dimensions of breathlessness and that D-12 and MDP contribute complementary information. Moreover, the instruments may be more useful for capturing certain aspects of breathlessness and QoL, as shown for D-12 in terms of physical QoL, and MDP emotional responses which most strongly captured influence on mental QoL. In relation to these associations with QoL, adding measuring with the other instrument (D-12 or MDP) did not contribute any independent information-but this is likely to vary depending on the aim of the measurement and the outcome.

The present findings can be interpreted to support the hypothesis that certain dimensions-especially stronger affective and emotional reactions, are more likely to induce behavioural adaptation, leading to the vicious circle of inactivity, deconditioning and worsening symptoms. ${ }^{33} 34$ For research, our findings can be relevant when selecting the appropriate instruments and scales in studies of breathlessness and QoL. The reliability and usefulness of the instruments for symptom monitoring in clinical practice is unknown. Further studies are also needed on the impact of different breathlessness dimensions on other outcomes, such as self-efficacy and mental coping with chronic breathlessness, function and on the effect of symptomatic treatments.

\section{CONCLUSION}

Across all dimensions, worse breathlessness is associated with worse physical and mental QoL. Physical QoL was most strongly correlated with sensory and perceptual dimensions scores, most strongly captured by D-12, whereas MDP emotional responses of breathlessness most strongly influenced mental QoL in elderly men in the population.

Contributors Conception and design: ME; data collection: M0 and ME; analysis: LC and ME; Interpretation: all authors; first draft: LC and ME; revisions and acceptance of the version to publish: all authors. ME accepts full responsibility for the work and the conduct of the study, had access to the data, and controlled the decision to publish.

Funding The study was funded by unrestricted grants from the Research Council of the Region of Blekinge, and from the Swedish Research Council (Dnr: 201902081).

Competing interests None declared.

Patient consent for publication Not applicable.

Ethics approval The VASCOL study and present analysis was approved by the Regional Ethical review board in Lund (Dnr 2008/676 and 2019/134).

Provenance and peer review Not commissioned; externally peer reviewed.

Data availability statement All data relevant to the study are included in the article or uploaded as online supplemental information.

Supplemental material This content has been supplied by the author(s). It has not been vetted by BMJ Publishing Group Limited (BMJ) and may not have been peer-reviewed. Any opinions or recommendations discussed are solely those of the author(s) and are not endorsed by BMJ. BMJ disclaims all liability and responsibility arising from any reliance placed on the content. Where the content includes any translated material, BMJ does not warrant the accuracy and reliability of the translations (including but not limited to local regulations, clinical guidelines, terminology, drug names and drug dosages), and is not responsible for any error and/or omissions arising from translation and adaptation or otherwise.

Open access This is an open access article distributed in accordance with the Creative Commons Attribution 4.0 Unported (CC BY 4.0) license, which permits others to copy, redistribute, remix, transform and build upon this work for any purpose, provided the original work is properly cited, a link to the licence is given, and indication of whether changes were made. See: https://creativecommons.org/ licenses/by/4.0/.

\section{ORCID IDs}

Jacob Sandberg http://orcid.org/0000-0003-1863-2033

Magnus Ekström http://orcid.org/0000-0002-7227-5113

\section{REFERENCES}

1 Moens K, Higginson IJ, Harding R, et al. Are there differences in the prevalence of palliative care-related problems in people living with advanced cancer and eight non-cancer conditions? A systematic review. J Pain Symptom Manage 2014;48:660-77.

2 Currow DC, Dal Grande E, Ferreira D, et al. Chronic breathlessness associated with poorer physical and mental health-related quality of life (SF-12) across all adult age groups. Thorax 2017;72:1151-3.

3 Ekström M, Schiöler L, Grønseth R, et al. Absolute values of lung function explain the sex difference in breathlessness in the general population. Eur Respir J 2017;49:1602047. doi:10.1183/13993003.02047-2016

4 Ekström M, Sundh J, Schiöler L, et al. Absolute lung size and the sex difference in breathlessness in the general population. PLoS One 2018;13:e0190876.

5 Grønseth R, Vollmer WM, Hardie JA, et al. Predictors of dyspnoea prevalence: results from the BOLD study. Eur Respir $J$ 2014;43:1610-20.

6 Johnson MJ, Yorke J, Hansen-Flaschen J, et al. Towards an expert consensus to delineate a clinical syndrome of chronic breathlessness. Eur Respir J 2017;49:1602277. doi:10.1183/13993003.02277-2016

7 Gysels M, Higginson IJ. Access to services for patients with chronic obstructive pulmonary disease: the invisibility of breathlessness. $J$ Pain Symptom Manage 2008;36:451-60.

8 Nishimura K, Izumi T, Tsukino M, et al. Dyspnea is a better predictor of 5-year survival than airway obstruction in patients with COPD. Chest 2002;121:1434-40.

9 Parshall MB, Schwartzstein RM, Adams L, et al. An official American Thoracic Society statement: update on the mechanisms, assessment, and management of dyspnea. Am J Respir Crit Care Med 2012;185:435-52.

10 Sandberg J, Ekström M, Börjesson M, et al. Underlying contributing conditions to breathlessness among middle-aged individuals in the general population: a cross-sectional study. BMJ Open Respir Res 2020;7:e000643.

11 Ramon MA, Ter Riet G, Carsin A-E, et al. The dyspnoeainactivity vicious circle in COPD: development and external validation of a conceptual model. Eur Respir J 2018;52:1800079. doi:10.1183/13993003.00079-2018

12 Kunik ME, Roundy K, Veazey C, et al. Surprisingly high prevalence of anxiety and depression in chronic breathing disorders. Chest 2005;127:1205-11.

13 Williams M, Cafarella P, Olds T, et al. Affective descriptors of the sensation of breathlessness are more highly associated with severity of impairment than physical descriptors in people with COPD. Chest 2010;138:315-22.

14 Bestall JC, Paul EA, Garrod R, et al. Usefulness of the Medical Research Council (MRC) dyspnoea scale as a measure of disability in patients with chronic obstructive pulmonary disease. Thorax 1999;54:581-6.

15 Currow DC, Chang S, Grande ED, et al. Quality of life changes with duration of chronic breathlessness: a random sample of communitydwelling people. J Pain Symptom Manage 2020;60:818-27.

16 Sundh J, Ekström M. Dyspnoea-12: a translation and linguistic validation study in a Swedish setting. BMJ Open 2017;7:e014490.

17 Ekström M, Sundh J. Swedish translation and linguistic validation of the multidimensional dyspnoea profile. Eur Clin Respir J 2016;3:32665.

18 Hegendörfer E, Doukhopelnikoff A, Degryse J-M. Validity and reliability of the multidimensional dyspnoea profile in older adults. ERJ Open Res 2021;7:00606-2020. 
19 Williams MT, John D, Frith P. Comparison of the Dyspnoea-12 and multidimensional dyspnoea profile in people with COPD. Eur Respir J 2017;49:1600773. doi:10.1183/13993003.00773-2016

20 Melville MR, Lari MA, Brown N, et al. Quality of life assessment using the short form 12 questionnaire is as reliable and sensitive as the short form 36 in distinguishing symptom severity in myocardial infarction survivors. Heart 2003;89:1445-6.

21 Wadell K, Webb KA, Preston ME, et al. Impact of pulmonary rehabilitation on the major dimensions of dyspnea in COPD. COPD 2013;10:425-35.

22 Olsson M, Engström G, Currow DC, et al. VAScular and chronic obstructive lung disease (VASCOL): a longitudinal study on morbidity, symptoms and quality of life among older men in Blekinge County, Sweden. BMJ Open 2021;11:e046473.

23 Sundh J, Bornefalk H, Sköld CM, et al. Clinical validation of the Swedish version of Dyspnoea-12 instrument in outpatients with cardiorespiratory disease. BMJ Open Respir Res 2019;6:e000418.

24 Ekström M, Bornefalk H, Sköld M, et al. Validation of the Swedish multidimensional dyspnea profile (MDP) in outpatients with cardiorespiratory disease. BMJ Open Respir Res 2019;6:e000381.

25 Morélot-Panzini C, Gilet H, Aguilaniu B, et al. Real-life assessment of the multidimensional nature of dyspnoea in COPD outpatients. Eur Respir J 2016;47:1668-79.

26 Yorke J, Moosavi SH, Shuldham C, et al. Quantification of dyspnoea using descriptors: development and initial testing of the Dyspnoea-12. Thorax 2010;65:21-6.
27 Sullivan MJL, Bishop SR, Pivik J. The pain catastrophizing scale: development and validation. Psychol Assess 1995;7:524-32.

28 Maras D, Balfour L, Tasca GA, et al. Breathlessness catastrophizing relates to poorer quality of life in adults with cystic fibrosis. J Cyst Fibros 2019:18:150-7.

29 Abdallah SJ, Faull OK, Wanigasekera V, et al. Opioids for breathlessness: psychological and neural factors influencing response variability. Eur Respir J 2019;54:1900275.

30 Ware JE, Kosinski M, Bayliss MS, et al. Comparison of methods for the scoring and statistical analysis of SF-36 health profile and summary measures: summary of results from the medical outcomes study. Med Care 1995;33:AS264-7931.

31 Backman H, Vanfleteren L, Lindberg A, et al. Decreased COPD prevalence in Sweden after decades of decrease in smoking. Respir Res 2020;21:283.

32 Borna E, Nwaru BI, Bjerg A, et al. Changes in the prevalence of asthma and respiratory symptoms in Western Sweden between 2008 and 2016. Allergy 2019;74:1703-15.

33 Spathis A, Booth S, Moffat C, et al. The breathing, thinking, functioning clinical model: a proposal to facilitate evidence-based breathlessness management in chronic respiratory disease. NPJ Prim Care Respir Med 2017;27:27.

34 Hutchinson A, Barclay-Klingle N, Galvin K, et al. Living with breathlessness: a systematic literature review and qualitative synthesis. Eur Respir J 2018;51:1701477. 